\title{
The Effects of Physical Training are Varied and Occur in an Exercise Type-Dependent Manner in Elderly Men
}

\author{
Mari L. Sbardelotto, Giulia S. Pedroso, Fernanda T. Pereira, Helen R. Soratto, Stella MS. \\ Brescianini, Pauline S. Effting, Anand Thirupathi, Renata T. Nesi, Paulo CL. Silveira, \\ Ricardo A. Pinho*
}

Laboratory of Exercise Biochemistry and Physiology, Graduate Program in Health Sciences, Health Sciences Unit, Universidade do Extremo Sul Catarinense, Criciúma, Santa Catarina, Brazil

[Received January 28, 2017; Revised February 8, 2017; Accepted February 9, 2017]

\begin{abstract}
Regular exercise can decrease the deleterious effects of aging and limit the development and progression of chronic disease in elderly people, depending on the type, intensity, frequency, and duration of exercise. This study aimed to investigate the potential protective effects of different physical training programs on oxidative stress parameters and inflammatory and neurotrophic mediators in the serum of elderly men. Healthy male volunteers [60 to 80 years; $n=55$ ] were divided into four groups: control [Ctr, $n=14$ ], aerobic training on dry land [ATdl, $n=12$ ]; and combined training on dry land [CTdl, $n=12$ ] or in water [CTw, $n=17$ ]. The training protocols were performed over 8 weeks, three times per week. Each 1 h session included 5 min warming-up exercise, 50 min specific training [aerobic, strength, or combined], and 5 min stretching. Blood samples were drawn $72 \mathrm{~h}$ before [baseline] the beginning of the 8 weeks' protocol and $48 \mathrm{~h}$ after the last training session, processed, and the serum was aliquoted and stored at $-70^{\circ} \mathrm{C}$ until biochemical assessment of oxidative damage, antioxidant system and neurotrophic, growth and inflammatory factors. Elevated BDNF or IGF-1 levels were observed in the ATdl or CTdl groups, respectively. Overall oxidative stress parameters were improved including reduced lipid oxidative damage and increased thioredoxin reductase and glutathione peroxidase activities and total glutathione. Significant decreases in the inflammatory mediators IL-6 and IL-8 were observed; IL-6 was more susceptible to the effects of type of physical training. Thus, the effects of training in elderly men vary in an exercise type-dependent manner.
\end{abstract}

Key words: aging, strength training, aerobic training, combined training, oxidative stress, inflammation

Human aging is a multifactorial process comprising different variables such as genetics, social conditions and lifestyle $[1,2]$. The loss of functional capacity is an inevitable process during this period of life that is especially dependent on the adopted lifestyle [3]. In this sense, physical inactivity is a risk factor that contributes to cardiovascular disease, type II diabetes mellitus, breast cancer and bowel cancer and thus, about $9 \%$ of overall rate of premature death in the western countries [4]. There is a strong evidence that regular exercise can decrease the deleterious effects of the aging process and limit the development and progression of chronic disease in elderly people [1].

Many studies have suggested that aging is directly related to a reduced antioxidant capacity and increased levels of reactive oxygen and/or nitrogen species [5-7]. In any type of tissues, the increased level of free radicles promotes damage in several cellular components and triggers the activation of specific signaling pathways. These effects have been shown to influence numerous

*Correspondence should be addressed to: Dr. R. A. Pinho. Health Sciences Unit, Universidade do Extremo Sul Catarinense, Av. Universitária, 1105 Bairro Universitário, 88806-000 Criciúma, Santa Catarina, Brazil. E-mail address: pinho@unesc.net

Copyright: ( $\odot 2017$ Sbardelotto ML et al. This is an open-access article distributed under the terms of the Creative Commons Attribution License, which permits unrestricted use, distribution, and reproduction in any medium, provided the original author and source are credited. 
cellular processes associated with aging such as sarcopenia and the development of age-related diseases [8].

The skeletal muscle mass decreases about $25 \%$ of total bodyweight by age of 75-80 years [9] and muscle strength is reduced $15 \%$ from the age of 50 , potentially reaching up to $30 \%$ [10]. The progressive decline in skeletal muscle mass usually accompanied by decreased muscle strength and functionality which occurs through the process of sarcopenia affecting neuromuscular transmission, muscle architecture, fibers composition, excitation-contraction coupling, and metabolism [11,12]. In additional, studies have also found that elderly people exhibit a chronic low grade inflammatory status associated with elevated serum levels of proinflammatory cytokines (TNF- $\alpha$ and IL-6) $[13,14]$. This inflammatory condition might cause and/or might be a consequence of cellular oxidative stressmediated by reactive oxygen species (ROS) and/or nitrogen (ERN) and is associated with damage to the skeletal muscles $[15,16]$.

Other factors including the reduction of serum neurotrophic and growth factor levels also appear to play a crucial role in the health of elderly people. For example, the reduction of brain-derived neurotrophic factor (BDNF) serum levels has been identified as a memory and cognitive deficit as well as a predictor of the risk of morbidity and mortality in the elderly [17] whereas insulin-like growth type 1 (IGF-1) and vascular endothelial growth factor (VEGF) exhibit direct correlation to the reduction of muscle mass and strength in this population $[18,19]$.

Considering the aging population of the developed countries, understanding of the aging has clinical and economical significance. An effective therapy to delay the physiological aging process will have a great impact on population. As oxidative stress plays an important role in these processes, the adoption of strategies that reduce oxidative stress or enhance antioxidant defense systems might yield anti-aging effects. In this context, several studies have shown that regular exercise promotes changes in oxidative stress parameters [20], increases the levels of neurotrophins such as BDNF [21, 22], and modulates growth factors [23] in the elderly. Furthermore, interventions including exercise [both aerobic and resistance training] demonstrate beneficial effects on lowgrade chronic inflammatory profiles [14]. However, the type, intensity, frequency, and duration of exercise seem to be decisive for these biochemical changes. In this sense, the aim of this study was to investigate the effects of different physical training programs on oxidative stress parameters and inflammatory and neurotrophic mediators in the serum of elderly men.

Table 1. Basal characteristics.

\begin{tabular}{|c|c|c|c|c|c|c|c|c|}
\hline \multirow{3}{*}{ Variable } & \multirow{2}{*}{\multicolumn{2}{|c|}{ Control }} & \multicolumn{6}{|c|}{ Training } \\
\hline & & & \multicolumn{2}{|c|}{ AT } & \multicolumn{2}{|c|}{ CTdl } & \multicolumn{2}{|c|}{ CTw } \\
\hline & Mean \pm SD & Min/Max & Mean \pm SD & Min/Max & Mean \pm SD & Min/Max & Mean \pm SD & Min/Max \\
\hline Age (yr) & $67.5 \pm 6.52$ & $60-78$ & $67.17 \pm 4.41$ & $60-75$ & $67.42 \pm 6.73$ & $60-78$ & $68.06 \pm 6.35$ & $60-79$ \\
\hline Body fat (\%) & $21.41 \pm 2.62$ & $16.29-26.55$ & $23.78 \pm 1.51$ & $20.82-26.75$ & $20.56 \pm 2.00$ & $16.63-24.48$ & $24.86 \pm 1.18$ & $22.55-27.17$ \\
\hline Lean mass (kg) & $57.01 \pm 1.88$ & $53.32-60.69$ & $65.35 \pm 2.00$ & $61.43-69.27$ & $56.91 \pm 1.73$ & $53.51-60.31$ & $61.90 \pm 1.55$ & $58.87-64.94$ \\
\hline BMI $\left(\mathrm{Kg} \cdot \mathrm{m}^{-2}\right)$ & $25.18 \pm 1.72$ & $21.80-28.57$ & $28.93 \pm 1.04$ & $26.90-30.97$ & $24.48 \pm 0.75$ & $23.02-25.95$ & $27.75 \pm 0.91$ & $25.96-29.53$ \\
\hline
\end{tabular}

\section{MATERIAL AND METHODS}

\section{Trial Design and participants}

It is a parallel randomized controlled trial conducted at a physical fitness complex in the state of Rio Grande do Sul, Brazil. The recruitment of the participants was conducted through the radio and the randomization was conducted by lot. The eligibility criteria to participate in this study was: no use of drugs or medications capable of inducing myopathy, no physical limitations or clinical diseases that might compromise the execution of the exercise, and at least 6 months immediately prior to the study without regular exercise. All selected subjects were instructed not to perform any type of physical training out of the study.

\section{Randomization and blinding}

A total of seventy six elderly people were interested to participate in this study but 21 elderly did not meet the inclusion criteria. The flowchart of the participants is 
described in figure 1. After the initial screening to observe the number of participants in fulfilling the inclusion criteria, the researchers wrote numbers $1-4$, indicating each group, in small a piece of papers, folded It and put in an opaque plastic bag. In exceptional cases, some participants were allocated in the groups to medical advice regardless of draw. Fifty five participants were randomly divided into four groups: control $(\mathrm{Ctr}, \mathrm{n}=14)$, aerobic training on dry land (ATdl, $\mathrm{n}=12)$; combined training on dry land (CTdl, $n=12)$; and combined training in water $(\mathrm{CTw}, \mathrm{n}=17)$. The sample size was not calculated. We chose the approach to widely publicize the research in a local radio and conducted the research with as many participants. The participants received explanations regarding the purpose and risks of the protocol and signed to accept the consent term. Participant characteristics are listed in Table 1. The study was approved by the Research Ethics Committee of the Universidade do Extremo Sul Catarinense (protocol number 119477/72012).

Table 2. Aerobic training program.

\begin{tabular}{|c|c|c|c|c|c|c|c|}
\hline Mesocycle & $\begin{array}{l}\text { Microcycle } \\
\text { (Weeks) }\end{array}$ & $\begin{array}{l}\text { Sessions per } \\
\text { mesocycle }\end{array}$ & $\begin{array}{l}\text { Series per } \\
\text { session }\end{array}$ & $\begin{array}{l}\text { Time of exercise } \\
\text { in the series }\end{array}$ & $\begin{array}{l}\text { Intensity } \\
\text { (\% Fcmáx) }\end{array}$ & $\begin{array}{c}\text { Time of active recovery } \\
\text { between series }\end{array}$ & Total time \\
\hline 1 & $1-2$ & 6 & 5 & $5 \mathrm{~min}$ & $70 \%$ & $1 \mathrm{~min}$ & $29 \min$ \\
\hline 2 & $3-5$ & 9 & 4 & $8 \mathrm{~min}$ & $75 \%$ & $1 \mathrm{~min}$ & $35 \mathrm{~min}$ \\
\hline 3 & $6-8$ & 9 & 3 & $15 \mathrm{~min}$ & $80 \%$ & $2 \mathrm{~min}$ & $47 \mathrm{~min}$ \\
\hline
\end{tabular}

\section{Training protocols}

Training protocols were performed over a total period of 8 weeks, three times per week. Each $1 \mathrm{~h}$ session was divided into three parts: 5 min warming-up exercise, 50 min specific training (aerobic, strength, or combined, see Tables 2, 3, and 4, respectively), and 5 min stretching exercise.

\section{Blood sample}

Blood samples $(10 \mathrm{~mL})$ were drawn $72 \mathrm{~h}$ before [baseline] the beginning of the 8 weeks' protocol and $48 \mathrm{~h}$ after the last training session. The blood samples were drawn from the antecubital vein, collected in vacutainers without additives, and centrifuged at $1500 \mathrm{rpm}$ for $10 \mathrm{~min}$ at $4{ }^{\circ} \mathrm{C}$. Aliquots of washed/lysed red blood cells and serum samples were stored at $-70^{\circ} \mathrm{C}$ until biochemical assays were performed.

Table 3. Combined training program on dry land.

\begin{tabular}{ccccccccccc}
\hline & \multicolumn{1}{c}{} & \multicolumn{1}{c}{ Strength exercise } & \multicolumn{3}{c}{ Aerobic exercise } \\
\hline Mesocycle & $\begin{array}{c}\text { Microcycle } \\
\text { (Weeks) }\end{array}$ & $\begin{array}{c}\text { Sessions } \\
\text { per } \\
\text { mesocycle }\end{array}$ & $\begin{array}{c}\text { Series } \\
\text { per } \\
\text { session }\end{array}$ & $\begin{array}{c}\text { Number of } \\
\text { repetition } \\
\text { in the } \\
\text { series }\end{array}$ & $\begin{array}{c}\text { Time of } \\
\text { Intensity } \\
\text { active } \\
\text { recovery } \\
\text { between } \\
\text { series }\end{array}$ & $\begin{array}{c}\text { Time of } \\
\text { exercise } \\
\text { in the } \\
\text { series }\end{array}$ & $\begin{array}{c}\text { Intensity } \\
\text { (\%) } \\
\text { Fcmáx) }\end{array}$ & $\begin{array}{c}\text { Time of } \\
\text { active } \\
\text { recovery } \\
\text { between } \\
\text { series }\end{array}$ & $\begin{array}{c}\text { Total } \\
\text { time }\end{array}$ \\
\hline 1 & $1-2$ & 6 & 3 & $12 \mathrm{X}$ & $60 \%$ & $2 \mathrm{~min}$ & $5 \mathrm{~min}$ & $70 \%$ & $1 \mathrm{~min}$ & $36 \mathrm{~min}$ \\
2 & $3-5$ & 9 & 3 & $10 \mathrm{X}$ & $70 \%$ & $2 \mathrm{~min}$ & $5 \mathrm{~min}$ & $75 \%$ & $1 \mathrm{~min}$ & $45 \mathrm{~min}$ \\
3 & $6-8$ & 9 & 3 & $08 \mathrm{X}$ & $80 \%$ & $3 \mathrm{~min}$ & $5 \mathrm{~min}$ & $80 \%$ & $1 \mathrm{~min}$ & $68 \mathrm{~min}$ \\
\hline
\end{tabular}

\section{Oxidative damage assessment}

The malondialdehyde (MDA) concentrations in the serum samples were determined by reverse phase high performance liquid chromatography (Agilent Technologies 1200 series; Santa Clara, CA, USA) according to Grotto et al. [24] using a thiobarbituric acid derivatization. A standard curve was prepared using malondialdehyde tetrabutylammonium salt at concentrations ranging from 0.5 to $5.0 \mu \mathrm{M}$. Results were expressed as $\mu \mathrm{mol} / \mathrm{L}$ MDA. Protein carbonylation was determined according to the method described by Levine et al. [25]. Protein carbonyl content was measured by labeled protein-hydrazone derivatives using 2,4dinitrophenylhydrazide. The concentration of 2.4dinitrophenylhydrazide was measured as absorbance 
difference against 2.4-dinitrophenylhydrazide blank at $370 \mathrm{~nm}$. The Sulphydryl groups content was determined using the 5-5'- dithiobis (2-nitrobenzoic acid) method (DTNB) (Sigma, St. Louis, MO, USA). The reaction was initiated by adding $30 \mu \mathrm{L}$ DTNB $(10 \mathrm{mM})$ to phosphatebuffered saline. After $30 \mathrm{~min}$ of incubation at room temperature, the absorbance at $412 \mathrm{~nm}$ was measured and the amounts of 5,5'-Dithiobis [2-nitrobenzoic acid] formed (equivalent to the amount of sulphydryl groups) was calculated using the technique developed by Aksenov and Markesbery [26].

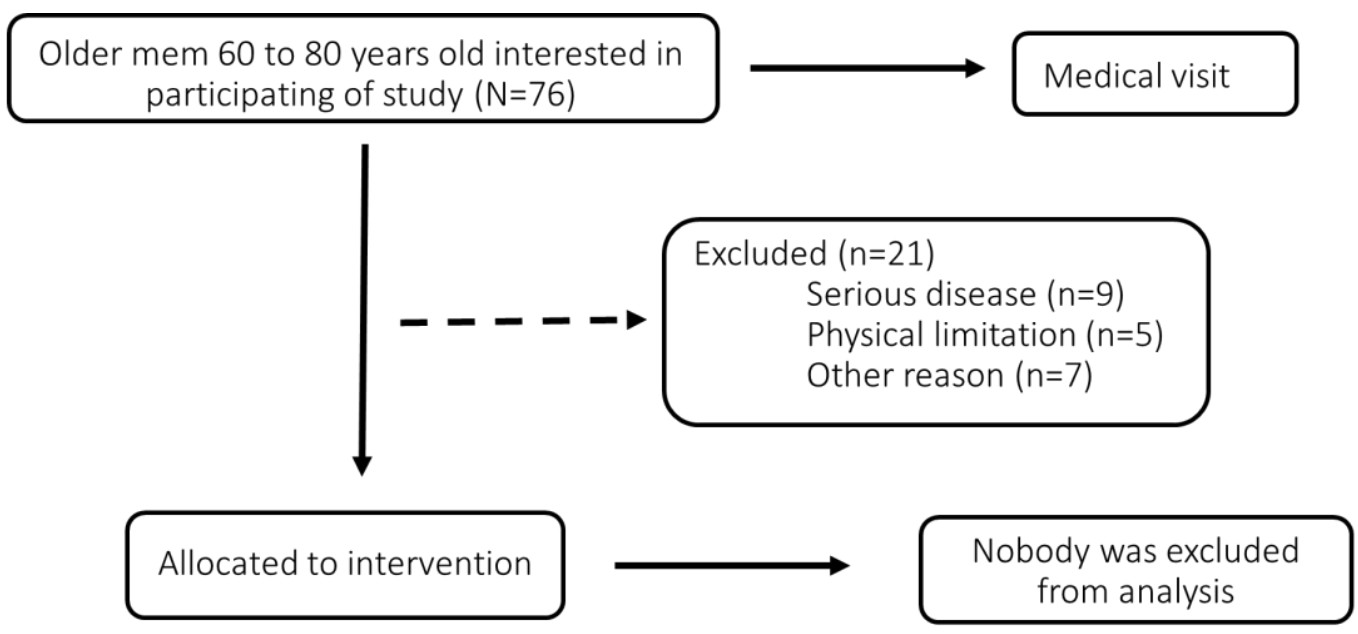

Figure 1. The flowchart of the participants.

\section{Antioxidant system assessment}

Catalase (CAT) activity was determined based on the hydrogen peroxide $\left(\mathrm{H}_{2} \mathrm{O}_{2}\right)$ decomposition rate generated by the enzyme present in the sample using a $10 \mathrm{mM} \mathrm{H}_{2} \mathrm{O}_{2}$ solution in potassium phosphate buffer, $\mathrm{pH} 7.0$ [27]. The maximum $\mathrm{H} 2 \mathrm{O} 2$ decomposition rate was measured at 240 $\mathrm{nm}$; the values were expressed as CAT units per mg protein. The glutathione peroxidase (GPx) activity was determined according Flohé and Gunzler [28]. An aliquot of the serum sample and $10 \mathrm{~mL}$ tert-butylhydroperoxide $(\mathrm{tBuOOH})$ were added to a mixture formed by a reaction medium. The $\mathrm{tBuOOH}$ catalyzed glutathione oxidation [GSH to GSSG] by GPx activity, which leads to the oxidation of NADPH as measured in a plate reader at 340 $\mathrm{nm}$. The values were expressed as $\mathrm{mM}$ NADPH $/ \mathrm{min} / \mathrm{mg}$ protein. Thioredoxin reductase (TrxR) activity was measured as the NADPH dependent colorimetric reduction of DTNB [29]. The samples were homogenized in $1 \mathrm{M}$ potassium phosphate buffer and enzyme activity was determined by DTNB reduction by NADPH with absorbance measured at $412 \mathrm{~nm}$ for $1 \mathrm{~min}$. TrxR activity was expressed in Units $/ \mathrm{mL} / \mathrm{mg}$ protein. Total GSH levels were determined as described by Hissin and Hilf [30] with modifications. GSH was measured in serum after protein precipitation with $10 \%$ trichloroacetic acid. An aliquot of the sample was added to phosphate buffer with $500 \mu \mathrm{M}$
DTNB. Color development resulting from the reaction between DTNB and the thiols reached a maximum in 5 min and was stable for more than $30 \mathrm{~min}$. Absorbance was read at $412 \mathrm{~nm}$ after $10 \mathrm{~min}$. A standard curve of reduced glutathione was used to calculate the GSH levels in the samples.

\section{Neurotrophic, growth factor, and inflammatory parameter assessment}

The serum levels of BDNF, IGF-1, interleukin $1 \beta$ (IL-1 $\beta$ ), interleukin 6 (IL-6), interleukin 8 (IL-8), and interleukin 10 (IL-10) were determined by commercially available ELISA kits (R\&D Systems, Minneapolis, MN, USA).

\section{Protein assay}

Protein levels were measured in all samples using the Bradford method [31], which is based on an absorbance $(595 \mathrm{~nm})$ shift of the dye Coomassie brilliant blue G-250 in which the red form of the dye is converted into its bluer form upon binding to the protein in the sample. Protein standards were obtained by diluting a stock solution of bovine serum albumin. Linear regression was used to determine the actual protein concentration of each sample. 
Table 4. Combined training program in water

\begin{tabular}{|c|c|c|c|c|c|c|c|c|c|c|}
\hline \multirow[b]{2}{*}{ Mesocycle } & \multirow[b]{2}{*}{$\begin{array}{c}\text { Microcycle } \\
\text { (Weeks) }\end{array}$} & \multirow[b]{2}{*}{$\begin{array}{c}\text { Sessions } \\
\text { per } \\
\text { mesocycle }\end{array}$} & \multirow[b]{2}{*}{$\begin{array}{c}\text { Series } \\
\text { per } \\
\text { session }\end{array}$} & \multicolumn{4}{|c|}{ Strength exercise } & \multicolumn{2}{|c|}{ Aerobic exercise } & \multirow[b]{2}{*}{$\begin{array}{c}\text { Total } \\
\text { time }\end{array}$} \\
\hline & & & & $\begin{array}{l}\text { Runtime } \\
\text { in the } \\
\text { series }\end{array}$ & $\begin{array}{c}\text { Speed of } \\
\text { execution }\end{array}$ & $\begin{array}{l}\text { Time of } \\
\text { active } \\
\text { recovery } \\
\text { between } \\
\text { series }\end{array}$ & $\begin{array}{l}\text { Time of } \\
\text { exercise } \\
\text { in the } \\
\text { series }\end{array}$ & $\begin{array}{c}\text { Intensity } \\
(\% \\
\text { Fcmáx })\end{array}$ & $\begin{array}{c}\text { Time of } \\
\text { active } \\
\text { recovery } \\
\text { between } \\
\text { series }\end{array}$ & \\
\hline 1 & $1-2$ & 6 & 2 & $30 \mathrm{sec}$ & maximum & $1 \mathrm{~min}$ & $10 \min$ & $70 \%$ & $1 \mathrm{~min}$ & $44 \mathrm{~min}$ \\
\hline 2 & $3-5$ & 9 & 3 & $20 \mathrm{sec}$ & maximum & $1 \mathrm{~min}$ & $15 \mathrm{~min}$ & $75 \%$ & $1 \mathrm{~min}$ & $49 \min$ \\
\hline 3 & $6-8$ & 9 & 4 & $15 \mathrm{sec}$ & maximum & $1 \mathrm{~min}$ & $20 \mathrm{~min}$ & $80 \%$ & $1 \mathrm{~min}$ & $59 \mathrm{~min}$ \\
\hline
\end{tabular}

\section{Statistical analysis}

The data were expressed as the means \pm standard error of the mean $[\mathrm{SEM}]$ and represent the number of times that the trained groups changed their values compared to control and baseline groups. The Kolmogorov-Smirnov test was used to confirm normal distribution of the values of all analyzed parameters. The Student's t-test was used to compare baseline versus post-training measures and one-way analysis of variance (ANOVA) followed by a Bonferroni post hoc test was used to detect the statistical difference between trained groups versus the control group. Differences were considered to be significant if $P$ $<0.05$. SPSS (version 21.0; Chicago, IL, USA) was used for all statistical analyses.

\section{Limitations}

This study has some limitations due to specificity of the population. We were not able to control the use of medications fully and stratify shorter age groups.
Although, we know that Dual-energy X-ray absorptiometry (DXA) is a reference assessment technique in muscle mass evaluation and it has been considered as a gold-standard technique for sarcopenia diagnosis. Unfortunately, we did not measure the body composition by this method due to technical limitations at the time of data collection.

\section{RESULTS}

Neurotrophic and growth factor changes in the elderly occurred in an exercise type-dependent manner: The levels of BDNF and IGF-1 were measured as neurotrophin and growth factor markers respectively. The results showed increased levels of BDNF and IGF-1 after physical training compared to baseline and control group levels (Fig. 2); however, these changes occurred in an exercise type-dependent manner. The BDNF levels were elevated in the ATdl group (Fig. 2A) whereas IGF-1 exhibited enhanced levels in the CTdl group (Fig. 2B).
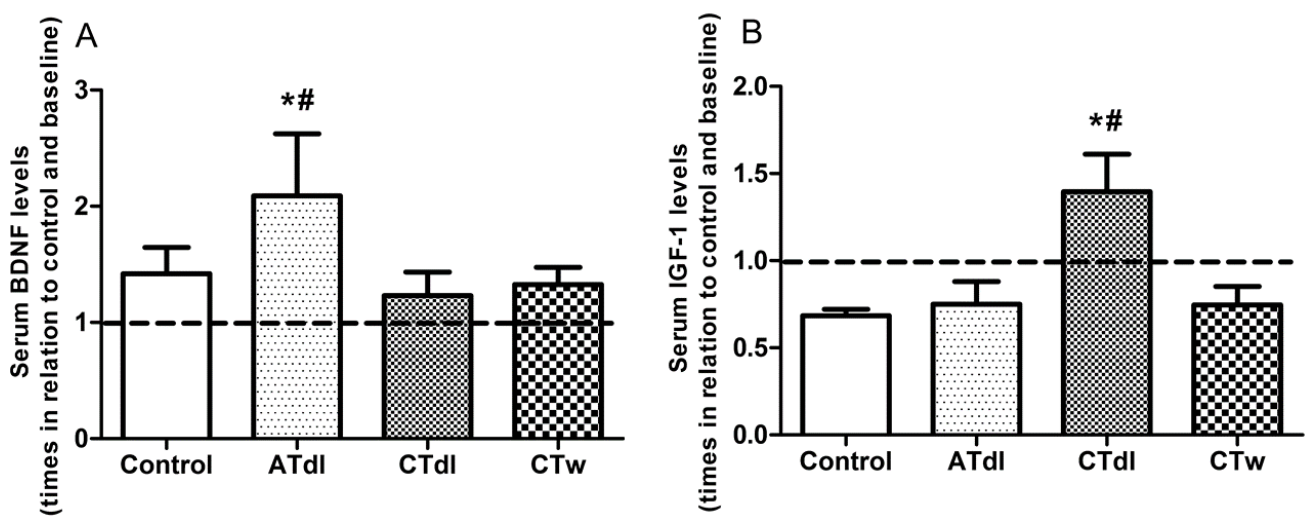

Figure 2. Effect of different physical training protocols on BDNF (A) and IGF-1 (B) levels. 55 elderly men performed over a total period of 8 weeks' sessions of aerobic training on dry land (ATdl), combined training on dry land $(\mathrm{CTdl})$, or combined training in water $(\mathrm{CTw})$. The dotted line represents the baseline. The values are presented as the means \pm standard error of the mean (SEM) and the results represent the number of times compared to baseline* or to the control group\# considering a significance index of $\mathrm{P}>0.05$ according to one-way ANOVA followed by Bonferroni's post-hoc test. 

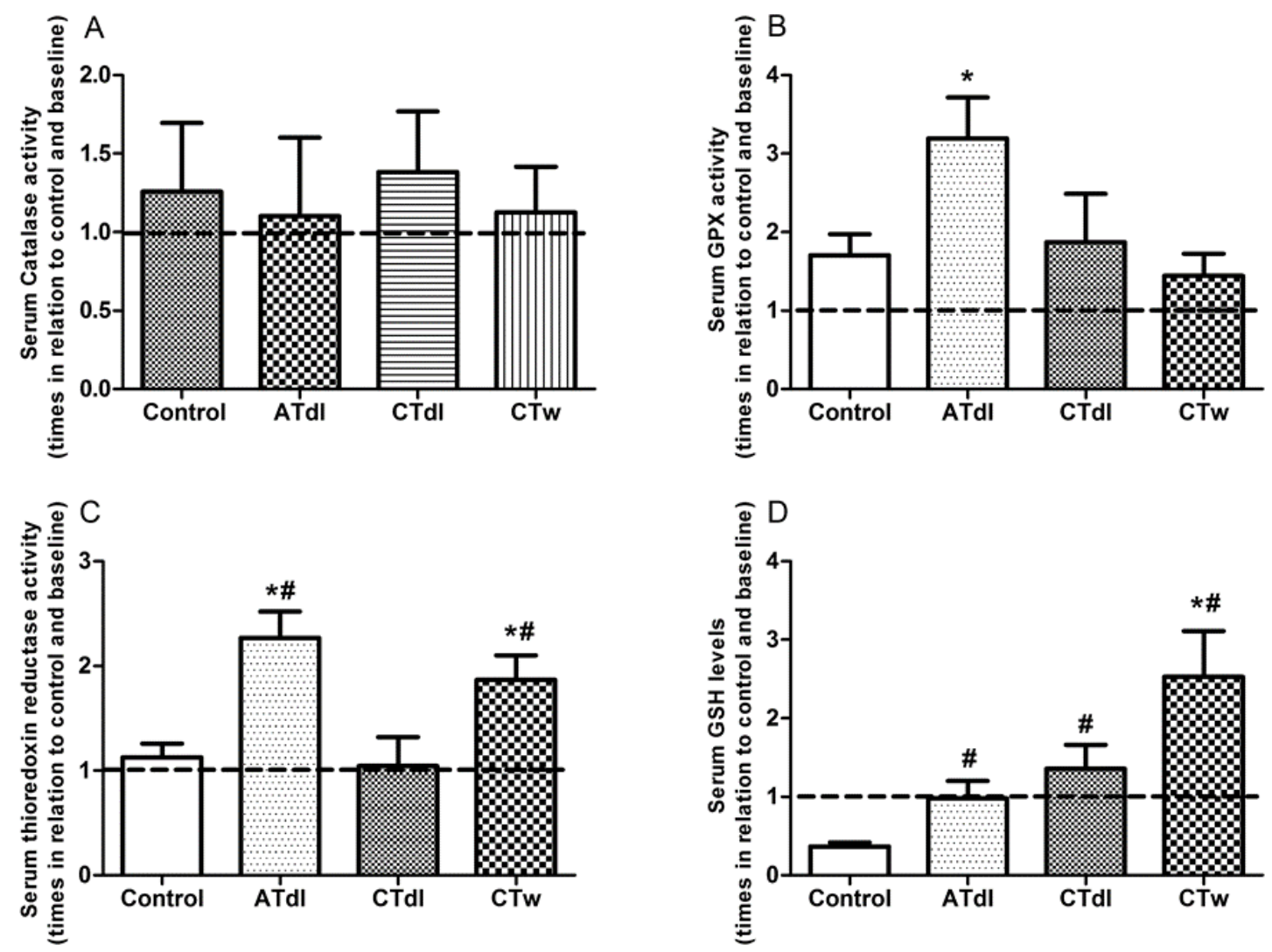

Figure 3. Effect of different training protocols on antioxidant system in elderly men after two months of physical exercise. aerobic training on dry land (ATdl), combined training on dry land (CTdl), or combined training in water (CTw) were performed three times a week for 60 min per session over a total period of 8 weeks. The dotted line represents the baseline. The values of catalase (A), GPx (B) and TRxR (C) activities and GSH levels (D) are presented as the means \pm standard error of the mean (SEM) and the results represent the number of times compared to baseline* or to the control group\# considering a significance index of $P>0.05$ according to one-way ANOVA followed by a Bonferroni's post-hoc test.

Effect of different physical training protocols on ageinduced changes in antioxidant levels in the serum: The antioxidant system was evaluated from measures of CAT, GPx, and TrxR activities along with total GSH/GSSH in the sera of elderly men (Fig. 3). No significant difference was found in the enzymatic activity of CAT (Fig. 3A). In contrast, GPx and TrxR activities were significantly changed. The ATdl group showed increased activity of GPx compared to baseline (Fig. 3B) whereas the CTw group showed enhanced activity of TrxR in relation to baseline as well as the control group (Fig. 3C) in both the ATdl and CTw groups. GSH, the major low-molecularweight antioxidant in serum, showed enhanced levels in all trained groups compared to the control group; however, only the CTw group showed elevated levels compared to baseline (Fig. 3D).
Increased oxidative damage in elderly men could be reversed by physical training: In this study, we investigated lipid damage (MDA levels) and the oxidation and modification of proteins via carbonyl group formation and the oxidation of sulphydryl groups (Fig. 4). Reduced levels of MDA were observed in all groups after physical training (Fig. 4A). Similarly, all groups showed reduced levels of carbonylated protein, but only the CTdl group exhibited values that were significantly decreased compared to both baseline and the control group (Fig. 4B). In contrast, sulphydryl group oxidation was not observed in the ATdl and CTdl groups whereas the CTw group showed enhanced levels of sulphydryl groups compared to baseline and the control group (Fig. 4C). 

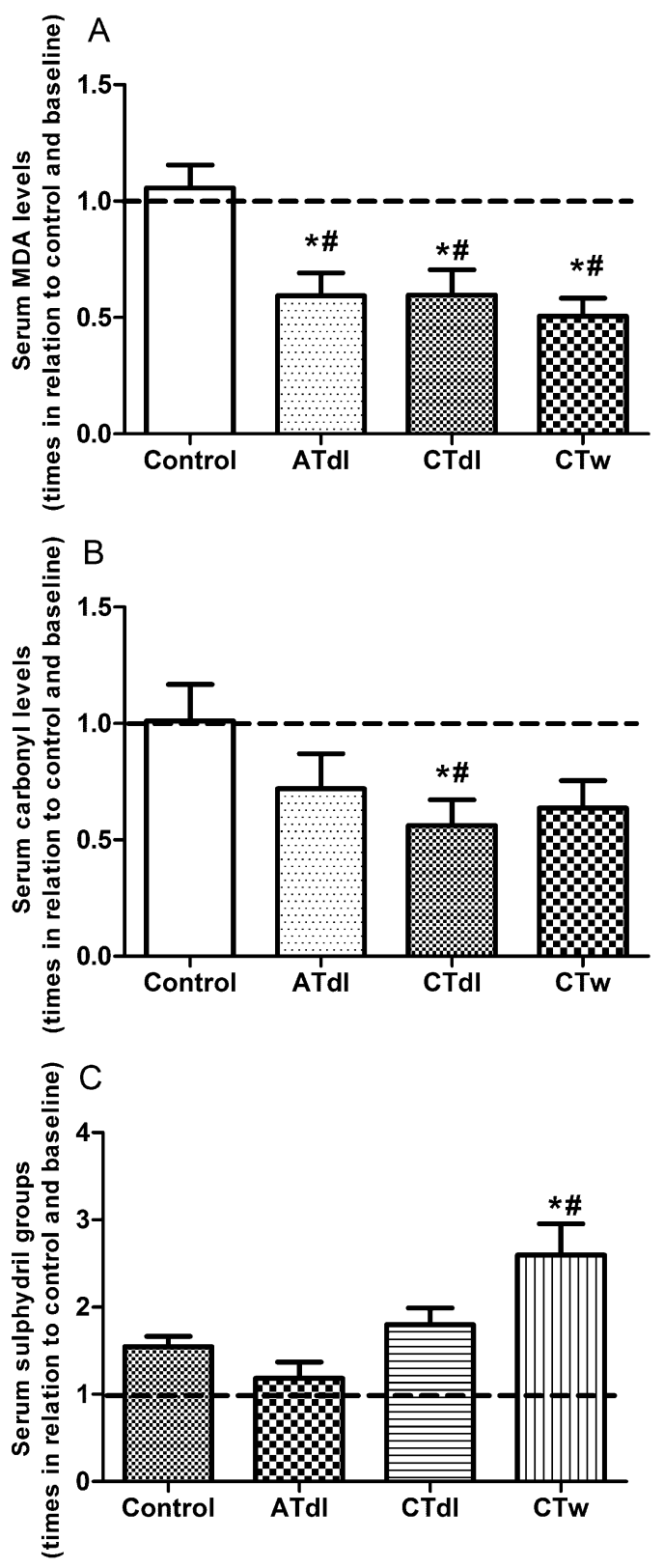

Figure 4. Changes in MDA (A), carbonyl groups (B), and Sulphydryl (C) levels induced by different training protocols in the elderly men. Two months of physical training with aerobic training on dry land (ATdl), combined training on dry land $(\mathrm{CTdl})$, or combined training in water $(\mathrm{CTw})$ were performed three times a week for 60 min per session over a total period of 8 weeks. The dotted line represents the baseline. The values are presented as the means \pm standard error of the mean (SEM) and the results represent the number of times compared to baseline* or to the control group\# considering a significance index of $\mathrm{P}>0.05$ according to one-way ANOVA followed by a Bonferroni's post-hoc test.
Physical activity modified the inflammatory profile in an exercise type-dependent manner in elderly men: Antiand pro-inflammatory interleukins were used to determine the inflammatory profile of elderly men (Fig. 5). The levels of IL-1 $\beta$ (Fig. 5A) and IL-10 (Fig. 5D) in the serum of the trained groups were unaltered compared to baseline and the control group. In contrast, the ATdl group showed significantly decreased levels of IL-6 (Fig. 5B) compared to baseline and of IL-8 (Fig. 5C) compared to the control group, whereas the CTdl group exhibited reduced IL-6 levels in relation to baseline and the control group. CTw treatment significantly reduced the levels of IL-8 only in relation to the control group.

\section{DISCUSSION}

Muscle wasting and loss of functional ability are frequently observed in the elderly and previous studies have suggested that these alterations might be partially associated with the constant and cumulative effects of ROS [32, 33]. Accordingly, physical exercise has been considered as one of the possible strategies to regulate the cellular redox state of elderly subjects $[7,34]$ as well as to reduce age-related muscle decline [2]. Although physical exercise has been proven to limit the development and progression of chronic disease and reduce the deleterious effects of aging, the mechanisms underlying the favorable effects of exercise during this phase of life are not fully understood.

Changes in the levels of neurotrophic and growth factors have been observed during aging that have been associated with sarcopenia [35]. For example, the anabolic effect of the IGF-1 growth factor on muscle tissue has been shown to stimulate muscle cell proliferation and differentiation, facilitate muscle protein synthesis, and inhibit its degradation [36]. Previous studies have also shown that low serum levels of IGF-1 were associated with losses in muscular strength, cognitive function, physical performance, and mortality in the aging population [37-39]. BDNF is a neurotrophin related to growth, differentiation, and neuronal plasticity that has many peripheral sources such as epithelial and vascular cells [40], macrophages and leucocytes [41], and muscle cells [42], which all have been shown to synthesize and release BDNF. Notably, reduced BDNF serum concentrations were consistently observed in adulthood psychiatric pathologies [43], and both IGF-1 and BDNF levels have been associated with the development of sarcopenia [35, 44].

Our results showed increased levels of BDNF and IGF-1 after physical training compared to baseline and the control group. Although it has been proposed that IGF-1 might interface with BDNF-mediated synaptic plasticity in the brain during exercise [38], this interface does not 
seem to manifest at the systemic level because the changes observed in our study occurred in an exercise typedependent manner. BDNF levels were elevated in the ATdl group whereas IGF-1 levels were increased in the CTdl group. Differences observed in both the ATdl and CTdl groups might be related to the type of training, as these two types of exercise differ primarily by the intensity of muscular contractions involved as well as the means by which energy is generated within the muscle. Combined exercise involves numerous muscle groups and mainly improves muscle resistance and strength while aerobic training has the central focus on improving cardiorespiratory fitness. Previous studies have shown that both BDNF and IGF-1 are dependent on the type of exercise performed. For example, Forti and colloegues [45] recently showed that only a mixed-low-resistance training program with a very high number of repetitions at a sufficiently high external resistance was able to increase circulating BDNF in older male participants. Furthermore, Goekint et al. [46] showed that strength training in sedentary male subjects did not influence serum BDNF. In addition, Taekema et al. [47] observed a relationship between IGF-1 levels and exercises for muscle strength in the oldest of elderly women.
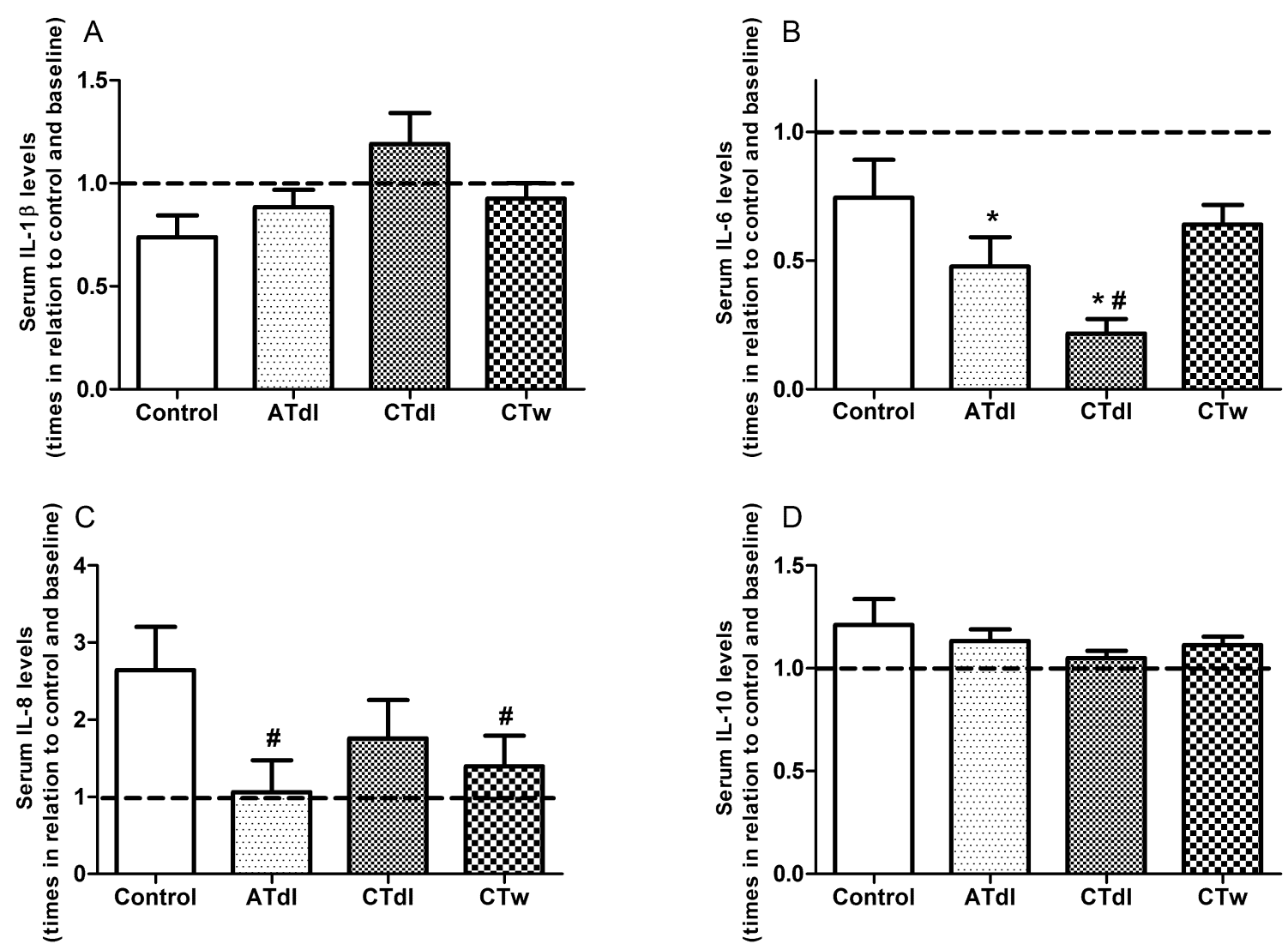

Figure 5. Effect of different training protocols on anti and pro-inflammatory parameters in elderly men. Two months of physical training with aerobic training on dry land (ATdl), combined training on dry land (CTdl), or combined training in water (CTw) were performed three times a week for $60 \mathrm{~min}$ per session over a total period of 8 weeks. The dotted line represents the baseline. The values of IL-1 $\beta$ (A), IL-6 (B), IL-8 (C) and IL-10 (D) levels are presented as the means \pm standard error of the mean (SEM) and the results represent the number of times compared to baseline* or to the control group\# considering a significance index of $\mathrm{P}>0.05$ according to one-way ANOVA followed by a Bonferroni's post-hoc test.

In addition to training type, two other factors might also be associated with changes in BDNF and IGF-1 levels in the sererum of elderly individuals: 1 ) the levels of oxidative stress and 2) the ability of physical training to modulate the muscle antioxidant defense system.
Oxidative stress might influence numerous cellular processes linked to aging and the development of agerelated diseases $[8,48]$ that are accompanied by muscle wasting [49]. According to Meng and $\mathrm{Yu}$ [6], the pathogenesis of sarcopenia is multifactorial and can be 
attributed to different factors such as oxidative stress, inflammation, endocrine changes, physical inactivity, and under-nutrition. Nonetheless, many of these factors do not act alone and many of their causal pathways intersect or overlap in relation to oxidative stress response. Therefore, a reduction in oxidative damage or increased efficacy of the antioxidant defense systems would likely promote significant effects toward anti-aging. Thus, the reduced levels of oxidative damage observed in our study might imply a reduction in ROS production or an improvement in the antioxidant defense system. Furthermore, this redox balance might be the major factor underlying the increase in BDNF and IGF-1 levels.

The enzymatic antioxidant system is the first line of cellular defense against ROS generation. Age-related changes in the expression and activity of antioxidant enzymes have been described in different tissues. In our study, the ATdl group showed increased activity of GPx compared to baseline alone whereas the CTw group showed enhanced activity of TrxR in relation to baseline as well as the control group in both the ATdl and CTw groups. Both GPx and TrxR-dependent peroxiredoxin proteins remove hydrogen peroxide and improve the control of intracellular redox states. From the results obtained using an experimental model, Sullivan-Gunn and Lewandowski [50] suggested that the decline in antioxidant protection by catalase and GPx is indicative of antioxidant dysfunction and might therefore act as a major contributing factor in the development or onset of sarcopenia. Nevertheless, there is no plausible explanation for the difference in the activity of these proteins between the different training models. However, aerobic training has been suggested as an important model to improve the enzymatic antioxidant defense system in humans [51, 52]. In addition, we observed elevated levels of GSH in all trained groups compared to the control group and following CTw compared to baseline. GSH plays a central role in antioxidant defenses and evidence from several human studies suggests that the concentrations of GSH decline with aging [53-55]. In response to exercise, the GSH levels at rest tend to increase as a cellular adaptation to the production of ROSinduced aging. In our study, CTw showed a more pronounced training effect on GSH levels. This suggests that $\mathrm{CTw}$ might exert a different stimulus on the glutathione system in the aged. In addition, the stimuli of strength and muscle strength associated with the aerobic components might have made a difference in the results obtained. Additional research is necessary to investigate this question further.

The positive effects of physical training on the antioxidant system reduce the possibility of oxidative damage in biomolecules. Among the oxidative damage markers analyzed in this study, the MDA level exhibited the most significant effect from physical training. Reduced levels of lipidperoxidation were observed in all groups after physical training as well as in relation to the control group. The low presence of end-products of lipid peroxidation in the serum reflects conditions of reduced levels of oxidative stress. Likewise, [56] recently showed decreased lipid peroxidation after 16 weeks of combined physical training in healthy middle-aged men and in elderly individuals. This result suggests that the effect of training on lipidperoxidation occurs in an exercise typeindependent manner in the elderly. In contrast, the antioxidant system changes observed in the current study suggested that the antioxidant system is dependent on the type of exercise performed. Therefore, the antioxidant defense system in serum might contain other antioxidant defense mechanisms that promote cellular protection and an equal response from different types of training. On the other hand, De Conzalo-Calvo and collegues [34] showed increased lipid peroxidation in middle-age men and in an aged population following long-term training with combined endurance and resistance activities. In this case, the time factor might have influence the elevated level of lipid peroxidation observed. Taken together, these data suggest that both the time and the type of exercise practiced by the elderly are crucial in the lipid peroxidation reduction induced by exercise.

Oxidative stress and inflammation are dependent processes that together are involved in many diseases associated with aging [14]. Age-related intracellular redox unbalance appears to be a primary causal factor in producing a chronic state of low-grade inflammation [6]. Notably, aging results in slight elevations of circulating proinflammatory mediators [57] and in alterations in Tcell function, immune cell senescence, alteration of the extracellular matrix, and increased fat mass and foci of chronic infection [14]. However, previous studies have also shown that regular physical exercise might mediate the anti-inflammatory response $[14,58,59]$. Thompson et al. [59] showed that the levels of IL-6 in serum decreased after 12 weeks of moderate resistance training in healthy middle-aged men compared to sedentary controls. Our results showed that the levels of IL-1 $\beta$ and IL-10, representing pro- and anti-inflammatory cytokines in the serum of the trained groups were not altered. Conversely, in the ATdl group the IL-6 levels were decreased significantly compared to baseline and those of IL-8 were reduced compared to the control group whereas the CTdl group exhibited reduced IL-6 levels in relation to both baseline and the control group. In comparison, the CTw group showed significantly reduced levels of IL-8 only in relation to the control group. Previous studies have shown that elevated serum IL-6 in aging is associated with different markers of physical ability. Taaffe and coauthors [60] found that IL-6 was positively linked with low 
walking speed and poor muscle strength and Cesari et al. [61] showed that elevated IL-6 levels were significantly associated with poor physical performance and muscle strength in older individuals. Therefore, although the overall interleukin levels are altered by exercise, IL-6 appear to be more susceptible to the effects of physical training than IL- 8 because the trained groups had lower levels of IL-8 in relation to the control group but these levels were not significantly reduced after the training programs.

In conclusion, the mechanisms of systemic adaptation induced by different models of training on dry land and in water are distinct, wherein each type of exercise activates different neurotrophic and growth factors as well as variably affects the regulation of cellular oxidative stress and inflammatory parameters. Taken together, these results show that the systemic changes related to aging mediated by physical training are dependent on the type of training accomplished; i.e., the effects of training are varied and occur in an exercise type-dependent manner. This study has important clinical implications because it suggests that the type of exercise practiced in the aged is directly related to modification of the desired parameters, which contradicts the standard dogma that the adherence to exercise is more important than the type of exercise performed.

\section{Acknowledgements}

This work was supported by the Research Program of the Brazilian Public Health System (SUS): Shared health management - PPSUS - MS/CNPq/FAPESC/SES referring to the public call for financial support 03/2012. Universidade do Extremo Sul Catarinense/Criciuma/SC/ Brazil, National Counsel of Technological and Scientific Development-CNPq/Brazil, and Coordination for the Improvement of Higher Education Personnel-CAPES/ Brazil also contributed to this work.

\section{Conflicts of Interest}

The authors declare that they have no conflicts of interest.

\section{References}

[1] Ciolac EG (2013). Exercise training as a preventive tool for age-related disorders: a brief review. Clinics, 68: 710-717.

[2] Zampieri S, Pietrangelo L, Loefler S, et al. (2015). Lifelong physical exercise delays age-associated skeletal muscle decline. J Gerontol A Biol Sci Med Sci, 70: 163-173.

[3] Deslandes A (2013). The biological clock keeps ticking, but exercise may turn it back. Arq Neuro Psiquiatr, 71: 113-118.
[4] Lee IM, Shiroma EJ, Lobelo F, Puska P, Blair SN, Katzmarzyk PT (2012). Effect of physical inactivity on major non-communicable diseases worldwide: an analysis of burden of disease and life expectancy. Lancet, 380: 219-229.

[5] Jackson MJ (2005). Reactive oxygen species and redox regulation of skeletal muscle adaptations to exercise. Philos Trans R SocLond B Biol Sci, 29: 2285-2291.

[6] Meng SJ, Yu LJ (2010). Oxidative Stress, Molecular inflammation and sarcopenia. Int J Mol Sci, 11: 15091526.

[7] Bouzid MA, Hammouda O, Matran R, Robin S, Fabre C (2014). Changes in oxidative stress markers and biological markers of muscle injury with aging at rest and in response to an exhaustive exercise. Plos One, 9: e90420.

[8] Finkel T, Holbrook NJ (2000). Oxidants, oxidative stress and the biology of ageing. Nature, 9: 239-247.

[9] Short KR, Vittone JL, Bigelow ML, Proctor DN, Nair KS (2004). Age and aerobic exercise training effects on whole body and muscle protein metabolism. Am J Physiol Endocrinol Metab, 286: E92-101.

[10] McClean RR, Kiel DP (2015). Developing consensus criteria for sarcopenia: an update. J Bone Miner Res, 30: 588-592.

[11] Cruz-Jentoft AJ, Baeyens JP, Bauer JM, et al. (2010). Sarcopenia: European consensus on definition and diagnosis- Report of the European working group on Sarcopenia in older people. Age Ageing, 39: 412-423.

[12] Burks TN, Cohn RD (2011). One size may not fit all: anti-aging therapies and sarcopenia. Aging [Albany NY], 3:1142-1153.

[13] Nicklas BJ, Brinkley TE (2009). Exercise training as a treatment for chronic inflammation in the elderly. Exerc Sport Sci Rev, 37:165-170.

[14] Beyer I, Mets T, Bautmans I (2012). Chronic low-grade inflammation and age-related sarcopenia. Curr Opin Clin Nutr Metab Care, 5:12-22.

[15] Howard C, Ferrucci L, Sun K, Fried LP, Walston J, Varadhan R, Guralnik JM, Semba RD (2007). Oxidative protein damage is associated with poor grip strength among older women living in the community. J Appl Physiol, 103:17-20.

[16] Woods JA, Wilund KR, Martin SA, Kistller BM (2012). Exercise, inflammation and aging. Aging Dis, 3:130140 .

[17] Tiedemann AC, Shimada H, Sherrington C, Murray S, Lord S (2008). The comparative ability of eight functional mobility tests for predicting falls in community-dwelling older people. Age Ageing, 37:430435.

[18] Kalleinen N, Polo-Kantola P, Irjala K, PorkkaHeiskanen T, Vahlberg T, Virkki A, Polo O (2008). 24Hour Serum Levels of Growth Hormone, Prolactin and Cortisol in Pre-and Postmenopausal Women: The Effect of Combined Estrogen and Progestin Treatment. J Clin Endocrinol Metab, 93:1655-1661.

[19] Maltais ML, Desroches J, Dionne IJ (2009). Changes in muscle mass and strength after menopause. J Musculoskelet Neuronal Interact, 9:186-197. 
[20] Radak Z, Marton O, Nagy E, Koltai E, Goto S (2013). The complex role of physical exercise and reactive oxygen species on brain. J Sport Health Sci, 2:87-93.

[21] Laske C, Stellos K, Hoffmann N, Stransky E, Straten G, Eschweiler G W, Leyhe T (2011). Higher BDNF serum levels predict slower cognitive decline in Alzheimer's disease patients. Int J Neuro Psycho Pharmacol, 14:399404.

[22] Coelho FM, Pereira DS, Lustosa LP, Silva JP, Dias JM, Dias RC, Queiroz BZ, Teixeira AL, Teixeira MM, Pereira LS (2012). Physical therapy intervention (PTI) increases plasma brain derived neurotrophic factor (BDNF) levels in non-frail and pre-frail elderly women. Arch Gerontol Geriatr, 54:415-420.

[23] Tsai CL, Wang CH, Pan CY, Chen FC (2015). The effects of long-term resistance exercise on the relationship between neurocognitive performance and GH, IGF-1, and homocysteine levels in the elderly. Front Behav Neurosci, 9:23.

[24] Grotto D, Santa Maria LD, Boeira S, Valentini J, Charão MF, Moro AM, Nascimento PC, Pomblum VJ, Garcia SC (2007). Rapid quantification of malondialdehyde in plasma by high performance liquid chromatography-visible detection. J Pharm Biomed Anal, 43:619-24.

[25] Levine RL, Garland D, Oliver CN, Amici A, Climent I, Lenz AG, Ahn BW, Shaltiel S, Stadtmann ER (1990). Determination of carbonyl content in oxidatively modified proteins. Methods Enzymol, 186:464-478.

[26] Aksenov MY, Markesbery WR (2001). Changes in thiol content and expression of glutathione redox system genes in the hippocampus and cerebellum in Alzheimer's disease. Neurosci Lett, 302:141-145.

[27] Aebi H (1984). Catalase in vitro. Meth Enzymol, 105:121-126.

[28] Flohé L, Gunzler W (1984). Assay of glutathione peroxidase. Methods Enzymol, 105:114-121.

[29] Holmgren A, Björnstedt M (1995). Thioredoxin and thioredoxin reductase. Methods Enzymol, 252:199-208.

[30] Hissin PJ, Hilf R (1976). A fluorometric method for determination of oxidized and reduced glutathione in tissues. Anal Biochem, 74:214-226.

[31] Bradford MM (1976). Rapid and sensitive method for the quantitation of microgram quantities of protein utilizing the principle of protein-dye binding. Anal Biochem, 72: 248-254.

[32] Ristow M, Schmeisser S (2011). Extending life span by increasing oxidative stress. Free Radic Biol Med, 15:327-336

[33] Dato S, Crocco P, D'Aquila P, de Rango F, Bellizzi D, Rose G, Passarino G (2013). Exploring the role of genetic variability and lifestyle in oxidative stress response for healthy aging and longevity. Int J Mol Sci, 14:16443-16472.

[34] De Gonzalo-Calvo D, Fernández-García B, de LuxánDelgado B, Rodríguez-González S, García-Macia M, Suárez FM, Solano JJ, Rodríguez-Colunga MJ, Coto-Montes A (2013). Chronic training increases blood oxidative damage but promotes health in elderly men. Age (Dordr), 35:407417.

[35] Kalinkovich A, Livshits G (2015). Sarcopenia-The search for emerging biomarkers. Ageing Res Rev, 22:58-71.

[36] Woodhouse LJ, Mukherjee A, Shalet SM, Ezzat S (2006). The influence of growth hormone status on physical impairments, functional limitations, and health related quality of life in adults. Endocr Rev, 26:287-317.

[37] Cappola AR, Bandeen-Roche K, Wand GS, Volpato S, Fried LP (2001). Association of IGF-I levels with muscle strength and mobility in older women. J Clin Endocrinol Metab, 86:4139-4146.

[38] Ding Q, Vaynman S, Akhavan M, Ying Z, GomezPinilla F (2006). Insulin-like growth factor I interfaces with brain-derived neurotrophic factor-mediated synaptic plasticity to modulate aspects of exerciseinduced cognitive function. Neurosci, 140:823-833.

[39] Kaplan RC, McGinn AP, Pollak MN, Kuller L, Strickler HD, Rohan TE, Xue X, Kritchevsky SB, Newman AB, Psaty BM (2008). Total insulin like growth factor 1 and insulin like growth factor binding protein levels, functional status, and mortality in older adults. J Am Geriatr Soc, 56:652-660.

[40] Nakahashi T, Fujimura H, Altar CA, Li J, Kambayashi J, Tandon NN, Sun B (2000). Vascular endothelial cells synthesize and secrete brain-derived neurotrophic factor. FEBS Letter, 470:113-117.

[41] Gielen A, Khademi M, Muhallab S, Olsson T, Piehl F (2003). Increased brain-derived neurotrophic factor expression in white blood cells of relapsing-remitting multiple sclerosis patients. Scand J Immunol, 57:493497.

[42] Matthews VB, Aström MB, Chan MH, et al. (2009). Brain- derived neurotrophic factor is produced by skeletal muscle cells in response to contraction and enhances fat oxidation via activation of AMP-activated protein kinase. Diabetologia, 52:1409-1418.

[43] Bocchio-Chiavetto L, Bagnardi V, Zanardini R, et al. (2010). Serum and plasma BDNF levels in major depression: a replication study and metaanalyses. World J Biol Psychiatry, 11:763-773.

[44] Scicchitano BM, Rizzuto E, Musarò A (2009). Counteracting muscle wasting in aging and neuromuscular diseases: the critical role of IGF-1. Aging, 13:451-457.

[45] Forti LN, Van Roie E, Njemini R, Coudyzer W, Beyer I, Delecluse C, Bautmans I (2015). Dose-and genderspecific effects of resistance training on circulating levels of brain derived neurotrophic fator (BDNF) in community-dwelling older adults. Exp Gerontol, 70:144-149.

[46] Goekint M, De Pauw K, Roelands B, Njemini R, Bautmans I, Mets T, Meeusen R [2010]. Strength training does not influence serum brain-derived neurotrophic factor. Eur J Appl Physiol, 110:285-293.

[47] Taekema DG, Ling CH, Blauw GJ, Meskers CG, Westendorp RG, de Craen AJ, Maier AB [2011]. Circulating levels of IGF1 are associated with muscle 
strength in middle-aged- and oldest-old women. Eur J Endocrinol, 164:189-196.

[48] Barreiro E, Coronell C, Lavina B, Ramirez-Sarmiento A, Orozcoevi M, Gea J [2006]. Aging, sex differences, andoxidative stress in human respiratory and limb muscles. Free Radic Biol Med, 41: 797-809.

[49] Moylan JS, Reid MB [2007]. Oxidative stress, chronic disease and muscle wasting. Muscle Nerve, 35:411-429.

[50] Sullivan-Gunn MJ, Lewandowski PA [2013]. Elevated hydrogen peroxide and decreased catalase and glutathione peroxidase protection are associated with aging sarcopenia. BMC Geriatr, 13:104.

[51] Parise G, Phillips SM, Kaczor JJ, Tarnopolsky MA [2005]. Antioxidant activity enzyme is up regulated after unilateral resistance exercise training in older adul ts. Free Radic Biol Med, 15:289-295.

[52] Nyberg M, Mortensen SP, Cabo H, Gomez-Cabrera MC, Viña J, Hellsten Y [2014]. Roles of sedentary aging and life long physical activity in exchange of glutathione across exercising human skeletal muscle. Free Radic Biol Med, 73:166-173.

[53] Samiec PS, Drews-Botsch C, Flagg EW, Kurtz JC, Sternberg P Jr, Reed RL, Jones DP [1998]. Glutathione in human plasma: decline in association with aging, agerelated macular degeneration, and diabetes. Free Radic Biol Med, 24:699-704.

[54] Elokda AS, Nielsen DH [2007]. Effects of exercise training on the glutathione antioxidant system. Eur J Cardiovasc Prev Rehabil, 14:630-637.

[55] Sekhar RV, Patel SG, Guthikonda AP, Reid M, Balasubramanyam A, Taffet GE, Jahoor F [2011]. Deficient synthesis of glutathione underlies oxidative stress in aging and can be corrected by dietary cysteine and glycine supplementation. Am J Clin Nutr, 94:847853.

[56] Soares JP, Silva AM, Oliveira MM, Peixoto F, Gaivão I, Mota MP [2015]. Effects of combined physical exercise training on DNA damage and repair capacity: role of oxidative stress changes. Age [Dordr], 37:97-99.

[57] Krabbe KS, Pedersen M, Bruunsgaard H [2004]. Inflammatory mediators in the elderly. Exp Gerontol, 39:687-699.

[58] Petersen AM, Pedersen BK [2005]. The antiinflammatory effect of exercise. J Appl Physiol, 98:1154-1162.

[59] Thompson D, Markovitch D, Betts JA, Mazzatti D, Turner J, Tyrrell RM [2010]. Time course of changes in inflammatory markers during a 6-mo exercise intervention in sedentary middle-aged men: a randomized-controlled trial. J Appl Physiol, 108:769779.

[60] Taaffe DR, Harris TB, Ferrucci L, Rowe J, Seeman TE [2000]. Cross-sectional and prospective relationships of interleukin-6 and C-reactive protein with physical performance in elderly persons: MacArthur studies of successful aging. J Gerontol A Biol Sci Med Sci, 55:709-715.

[61] Cesari M, Penninx BWJH, Pahor M, Lauretani F, Corsi AM, Williams GR, Guralnik JM, Ferruci L [2004]. Inflammatory markers and physical performance in older persons: the In CHIANTI study. J Gerontol A Biol Sci Med Sci, 59:242-248. 